\title{
The Altemeier Procedure for Strangulated Rectal Prolapse: A Case Report
}

\author{
Amal Hajri, Karim Yaquine, Saad Rifki El Jai, Rachid Boufettal, Driss Errguibi, and Farid Chehab
}

\begin{abstract}
Rectal prolapse is the complete protrusion of the rectum through the anal canal. It is most common in elderly people, but can rarely occur at any age, the strangulated rectal prolapse is a rare complication. We report the case of a 78-year old men who underwent emergency surgery for strangulated rectal prolapse. Emergency perineal rectosigmoidectomy (Altemeier repair) was performed with simple outcome.

This case highlights the importance of Altemeier's procedure in the face of a strangulated rectal prolapse in an emergency situation.

Index Terms-Altemeier's procedure; perineal rectosigmoidectomy; rectal prolapse, strangulation.
\end{abstract}

\section{INTRODUCTION}

Rectal prolapse results in a rectal static disorder which involves rectal wall, intussusception inducing its externalization through the anus. It usually affects both children and the elderly. On rare occasions becomes complicated by irreducibility. The organ becomes edematous, and begins to ulcerate and gangrenous, requiring emergency surgery [1].The choice of surgical procedure depends mainly on patient's age, clinical condition, surgical risk, coexisting functional symptoms, and the surgeon's experience with a particular surgical approach [2].

\section{Case report}

It is a 78-year-old men admitted to the emergency department with a painful mass protruding through the canal anal evolving over five days. On admission, the patient presented with normal vital signs and was hemodynamically stable.

He reported a sudden protrusion of a mass through the anus during defaecation, with significant anal pain. The patient had medical history of constipation, rectal hemorrhage and several episodes of rectal prolapse manually reduced. Physical examinations showed no signs of abdominal distension or peritonitis, and no other physical abnormality. The proctology examination found a rectal prolapse strangulated, with edema and mucosal ulcerations measuring 7 of length by $6 \mathrm{~cm}$ wide (Figure 1).
Published on March 27, 2020.

Authors are with Ibn Rochd University Hospital, Casablanca, Morocco. (corresponding e-mail: amalhajri.282@gmail.com)

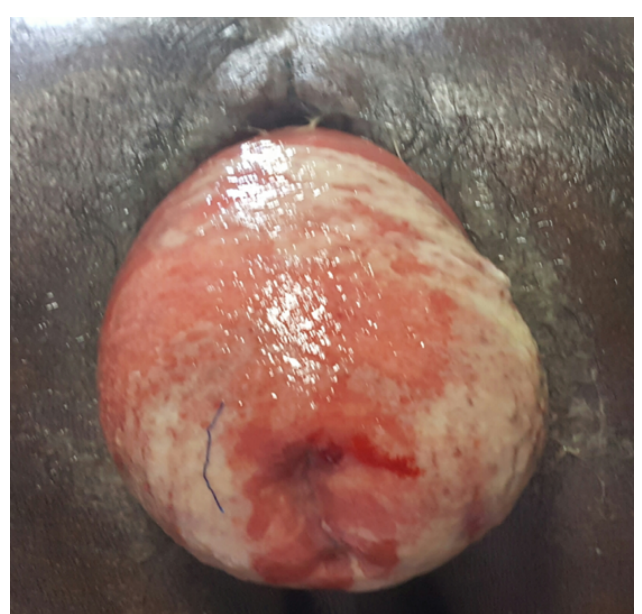

Fig. 1. Edematous and irreducible rectal prolapse.

Following the failure of external manual reduction and the appearance of established necrosis, we decided to perform an emergency surgery. He had undergone rectosigmoidectomy with colo-anal anastomosis by perineal route according to the Altemeier technique: the rectum was sectioned just above the pectine line, the colon lowered transanally was sectioned opposite the pectine line.

Colon-anal anastomosis was performed manually with interrupted sutures, with sigmoid colostomy (Figure 2). The postoperative was unevent. The follow up in a year noted no recidivism of rectal prolapse. The specimen pathophysiology examination revealed an inflammed mucosa with ulceration.

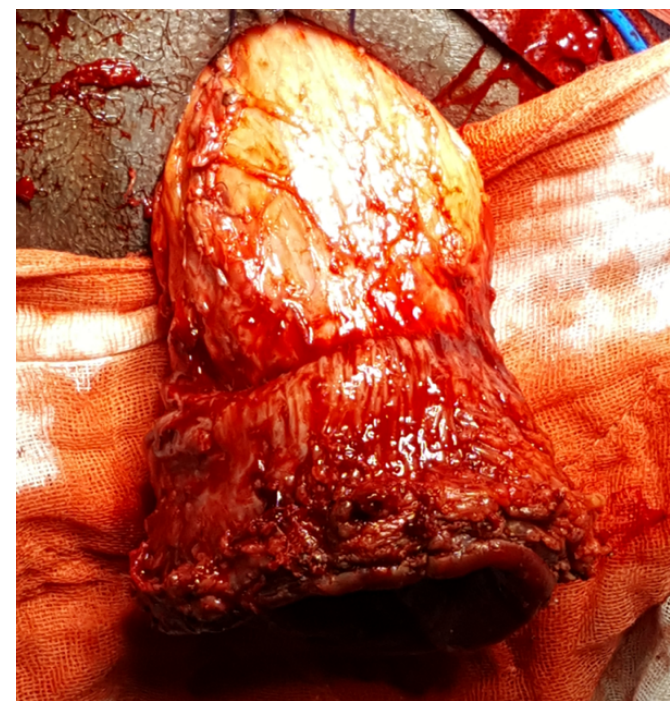

Fig. 2. Altemeier operation: A lowering colon divided next to the dentate line. 


\section{DISCUSSION}

The estimated prevalence of rectal prolapse in adults over 65 year old is $1 \%$. It can be associated with significant morbidity including rectal bleeding, chronicle constipation, rectal pain and possible strangulation [3].There are many contributing factors: constipation, pregnancies, diastasis of the levators, redundant sigmoid colon, deep cul-de-sac, abnormal rectal angle, and lack of retroperitonealization of the rectum [4].

Prolapse may be spontaneous or caused by standing or coughing. Other symptoms, sometimes associated are constipation, incomplete evacuation, rectal bleeding, rectal pain, incontinence, the urge to have a bowel spasm, and tenesmus [5]. Strangulation of rectal prolapse is a rare complication that occurs in $2-4 \%$ of cases [6].

Important signs of strangulation include irreducibility, rectal pain, edema, swollen mucosa and purplish red appearance. When this initial stage passes, the mucosa becomes cyanotic [3].

There is still no clear consensus to the technique to use in the management of strangulated rectal prolapse.

Every effort should be made to reduce manually a persistently prolapsed rectum, with taking care of possible complications such as strangulation, ulceration, bleeding and perforation [2].

These conservative methods aim to reduce the edema and allow reduction of the prolapse, with a programmed surgery. Edema may be reduced by the application of sugar, injection of hyaluronidase, or applying an elastic compression wrap [3].

Where prolapse is irreducible with ischemic signs, surgical treatment is required.

There are a large number of perineal and abdominal approaches that have been useful in treating rectal prolapse in elderly and high-risk patients, but perineal rectosigmoidectomy (Altemeier's procedure) with or without a protective stoma is the most accepted because it is simple, recurrence is infrequent, and has a low morbidity and mortality rates [7].

In perineal rectosigmoidectomy (Altemeier procedure), the prolapsed rectum and redundant colon are resected and the proximal colon is removed through the perineum. A manual or mechanic anastomosis is coloanal anastomosis is perfomed .Recent series (combined with levatorplasty and Altemeier procedure) revealed excellent results and inspired this ongoing consecutive series of cases [8]. A low incidence of complications has been described, around 10 $12 \%$. Anastomotic leak is the most common serious complication in postoperative with pelvic abscess, urogenital dysfunction, and anastomotic stenosis.

According the indication to perform a protective colostomy during the process, about one quarter of the reviewed authors indicated a protective colostomy when there were local conditions that involved a higher risk of anastomotis leak or in patients with previous incontinence, as in our case [9].

The Delorme procedure is difficult in this situation because of the edema and is contraindicated in the case of necrosis [10].

Abdominal approach do not provide access for levatorplasty. Moreover, there are a great variety of complications directly associated with abdominal repairs of rectal prolapse, such as bandle obstruction, wound infection, eventration, and sexual dysfunction in men [11].

\section{CONCLUSION}

Strangulation of an acute rectal prolapse is a rather unusual entity that represents a surgical emergency. The type of surgery for patients with rectal prolapse should be selected after taking the patient's general condition and the surgeon's experience into account. Because it has lower recurrence, morbidity and mortality rates than does abdominal surgery, Altimeter's procedure is the preferred surgical option for incarcerated or strangulated rectal prolapse especially for patients who require resection, for debilitated elderly.

\section{REFERENCES}

[1] Bayar R, Djebbi A, Mzoughi Z, Talbi G, Gharbi L, Arfa N, et al. Prolapsus rectal étranglé de l'adulte jeune: à propos d'un cas et revue de la littérature. Pan Afr Med J [Internet]. 2016 [cité 23 mars 2020];25. Disponible sur: http://www.panafrican-med journal.com/content/article/25/60/full/

[2] Lopez Guzman CM, Salcedo Miranda DF. Rectosigmoidectomía perineal (Procedimiento de Altemeier) para el prolapso rectal encarcelado: reporte de un caso. Rev Colomb Gastroenterol. 19 déc 2018;33(4):454.

[3] Seenivasagam T. Irreducible Rectal Prolapse: Emergency Surgical Management of Eight Cases and A Review of the Literature. 2011; 66(2):3.

[4] Li JZ, Kittmer T, Forbes S, Ruo L. Case report: Sigmoid strangulation from evisceration through a perforated rectal prolapse ulcer - An unusual complication of rectal prolapse. Int J Surg Case Rep. 2015; 10:238-40.

[5] Goldstein S, Maxwell P. Rectal Prolapse. Clin Colon Rectal Surg. mars 2011;24(01):039-45.

[6] $\mathrm{Li}$ et al. - 2015 - Case report sigmoid strangulation from eviscerati.pdf.

[7] Takesue Y, Yokoyama T, Murakami Y, Akagi S, Ohge H, Yokoyama $\mathrm{Y}$, et al. The effectiveness of perineal rectosigmoidectomy for the treatment of rectal prolapse in elderly and high-risk patients: 4 .

[8] Barfield L. Perineal Approaches to Rectal Prolapse. Clin Colon Rectal Surg. 22 déc 2016;30(01):012-5.

[9] Cernuda RB, Ángel JP, Fernández NT, Sánchez-Farpón JH, Pérez JAÁ. Perineal Rectosigmoidectomy (Altemeier Procedure) as Treatment of Strangulated Rectal Prolapse. J Gastrointest Surg. déc 2016; 20(12):2102-3.

[10] Ben Ameur H, Rejab H, Beyrouti MI. Altemeier Operation for Recurred and Strangulated Rectal Prolapse. Indian J Surg. juin 2013; 75(S1):224-6.

[11] Cirocco WC. The Altemeier Procedure for Rectal Prolapse: An Operation for All Ages: Dis Colon Rectum. Déc 2010; 53(12):1618-23.

\section{Amal Hajri}

Casablanca, Morocco 20400

Telephone: 00212613299259

e-mail: amalhajri.282@gmaill.com

Institution: Department of General Surgery III, Ibn Rochd University Hospital, Casablanca, Morocco.

\section{Karim Yaquine}

e-mail: yaqine.karim@gmail.com

Institution: Department of General Surgery III, Ibn Rochd University Hospital, Casablanca, Morocco.

\section{Saad Rifki El Jai}

e-mail: Saadjai@yahoo.fr

Institution: Department of General Surgery III, Ibn Rochd University Hospital, Casablanca, Morocco.

Rachid Boufettal

e-mail: racbouf@hotmail.fr 
Institution: Department of General Surgery III, Ibn Rochd University Hospital, Casablanca, Morocco.

\section{Driss Errguibi}

e-mail: erguibi_d@yahoo.fr

Institution: Department of General Surgery III, Ibn Rochd University Hospital, Casablanca, Morocco.

\section{Farid Chehab}

Head of the digestive cancer and liver transplant surgery department and head of the surgery department.

e-mail: Farid_chehab@yahoo.fr

Institution: Department of General Surgery III, Ibn Rochd University

Hospital, Casablanca, Morocco. 